\title{
Cognitive and Motivational Components of Successful Learning Activity in Students Having Different Lateralization of Brain Function
}

\author{
Mergalyas Kashapov \\ Doctor of Psychological Sciences, Professor, Head of the Chair of Pedagogics and \\ Pedagogical Psychology P.G. Demidov Yaroslavl State University; smk007@bk.ru \\ Tatiana Ledovskaya \\ Candidate of Psychological Sciences, Associate Professor, Chair of Pedagogical Psychology \\ K.D. Ushinskiy Yaroslavl State Pedagogical University; karmennnn@yandex.ru
}

Doi:10.5901/mjss.2015.v6n6s5p304

\section{Abstract}

\begin{abstract}
The goal of the research is studying the cognitive and motivational characteristics of learning activity success in students having different type of interhemispheric lateralization of brain function. The following methods were used for diagnostics: 1) performances of learning activity were determined a) using the technique "Integrated diagnostics of students' readiness for studying at a higher education institution" (the structural index); 2) using the qualitative analysis of academic progress during the assessment (effective index); 2) functional tests were used for determining the type of brain function lateralization. The following results were obtained: 1) psychological structure of the learning activity in dextrocerebral students is less developed while that in sinistrocerebral ones is more developed and is characterized by the complete set of components having the optimum quantity of links between qualities that are important for learning. For the psychological structure of learning activity, the level and quality of development are determined by the total of cognitive and motivational academically important qualities; 2) distinctions in learning activity success have been revealed between students of different brain function lateralization type. With the same values of learning activity structural index, the specific character of component and structural-functional characteristics of the psychological structure of learning activity is evident; it is explained by students' cognitive processes particularities and behavioral ones.
\end{abstract}

Keywords: learning activity success, lateralization of brain function.

\section{Introduction}

Human cognitive development belongs to the most vital issues of today's psychological science. Formation of a competitive person is impossible without the cognitive processes of development which are the basis of intellectuality. Study of cognitive processes becomes relevant due to ongoing change in the contemporary society. The higher professional education faces the objectives of developing the students' cognitive capacities, as their further efficiency in any professional activity is impossible without highly developed cognitive capacities.

\subsection{Literature review}

The contemporary conditions are also characterized by the changing requirements for the procedure and quality of higher education institution students' training in the context of both cognitive, motivational, social and psychological development. This is reflected on studying the readiness for learning (N.V. Nizhegorodtseva, V.D. Shadrikov), creative thinking development (M.M. Kashapov et al.), the students' professional rise and individual particularities (M.M. Kashapov, Yu.P. Povarenkov et al.). However, it is not only the cognitive qualities but also motivational ones that promote students' successful inclusion into the academic and professional activity. The increasing requirements for students' social, psychological, behavioral, cognitive and personal characteristics at large at the stage of their inclusion into the academic and professional activity also raise the relevance of studying the contribution of the cognitive and motivational aspects to learning activity development in representatives of this age group.

The topic of our research is directly associated with the basic notions of psychology such as "activity", "learning activity", "psychological structure of activity", "learning activity success" etc. Given this, some comments should be made 
on defining the scientific terms required.

The scientific literature views activity in three aspects: 1) subject-active aspect; 2) psychological aspect (individual human qualities); 3) physiological aspect (Shadrikov, 1982). The problem of psychological structure of learning activity at all levels of study, indices/criteria of its success and efficiency, identification of its main structural components is one of the significant ones in the contemporary psychological and pedagogical science. The psychological aspects of content of the notion "learning activity" are the subject of consideration of many Russian and foreign researchers. According to the systemogenetic concept of learning and professional activity, the structure of activity is an "integral unity of the components and their comprehensive connections which embody the activity" (Shadrikov, 1982). The psychological structure of learning activity (PSLA) is determined as an integral unity of the academically important qualities and their comprehensive connections which induce, program, regulate and implement the activity (Nizhegorodtseva, 2004). The author singles out 5 functional units filled with academically important qualities (AIQ) the entirety of which forms the psychological structure of the academic activity (Nizhegorodtseva, 2004):

- $\quad$ personality and motivation unit: the need of achievement (NA), the attitude to oneself (AO), empathy (EM);

- $\quad$ study task acceptance unit: acceptance of tasks (TA), professional focus (PF);

- $\quad$ the unit of ideas about the content and ways of performance of the learning activity: input skills (IS);

- activity information basis unit: logical memory (LM), verbal memory (VM), productivity of attention (PA), logical thinking (LT), flexibility of thinking (FT);

- activity control unit: capacity to study (CS), and voluntary regulation of activity (VRA).

Together with V.D. Shadrikov, we understand that the real human activity has non-additive character - it cannot be broken down into levels and components practically, and all units of psychological structure of learning activity are interrelated. However, within this research due to its applied orientation, the psychological structure of learning activity is represented by us as a psychological structure of learning activity of academically important qualities.

Yu.P. Povarenkov divides the process of education in a pedagogical higher education institution into 2 main periods. It is within them that the professional rise of students takes place the academic learning period (years 1-3) and the professional learning period (end of year 3, years 4 and 5 ) the content of which is reorientation of the academic learning activity to the professional pedagogic one (Povarenkov, 2013).

Within our research, it has been grounded that the learning activity success in higher education institution students has to be expressed by two indices: the effective one (the academic achievement level) and the structural one (the level of formation of the psychological structure of learning activity). The learning activity is considered to be successful then when the two indices correspond to the normative one: the effective index is determined by the federal state educational standard of the higher professional education and is expressed in the students' academic achievement level (the results of intermediate assessment of students), and the structural index is determined by formation of the psychological structure of learning activity, i.e. it implies an integral unity of academically important qualities making it up (Ledovskaya, 2010).

It is only in the second half of the XIX century that the human individual and typological particularities as an independent psychological and pedagogical problem became the subject of scientists' research. The higher interest for the problem was promoted by the higher quantity of psychological studies conducted within the psychology becoming an independent scientific discipline. The theoretical analysis of approaches has demonstrated that this problems range was a subject of attention of various theoretical and practical research within the psychology of individual distinctions, differential psychology etc. During the rise and development of these branches of psychology, their conceptual framework was determined: the main components of the notion "individuality", "individual particularities" were defined, and directions of studying the human individual particularities in practice were formed. As grounds for differentiating the people according to the type of individual distinctions, in various times, such mental properties as character, abilities, motivation, intellectual sphere particularities, mental and physiological particularities (properties of the nervous system, psychodynamic properties, particularities of brain hemispheres lateralization) etc. were adopted. In our study, we intended to analyze the influence of stable individual particularities which allow referring people to a certain category or group having a non-overlapping, inborn, hereditary and stable individual characteristics, i.e. with a different extent of individual and typological particularities.

According to this, we assume that the success of learning activity at large and that of higher education institution students in particular is closely associated with the individual and typological particularities. Within this work, we have selected and analyzed the lateralization of brain functions (a type of interhemispheric brain function lateralization) of the entire set of individual and typological particularities singled out by authors. Currently, the science views the type of interhemispheric lateralization of brain function (LBF) as a characteristic of mental functions distribution between the right and the left cerebral hemispheres, i.e. specific particularities of structure and functions of cerebral hemispheres: when 
performing certain mental functions, the left one dominates while the right one dominates when doing others. Today, it is commonly believed that there are three types of brain function lateralization: the right one, the left one, and ambidexterity. Lateralization of mental functions can be viewed as one of the most important phenomena taking part in forming not only different thinking styles in man but also in his inclinations and abilities, emotional response forms, adaptation particularities and other properties.

\section{Research Methods}

The goal is to study the cognitive and motivation characteristics of learning activity success in students having different brain function lateralization.

Objectives:

1. To develop a methodical complex for diagnosing and analyzing the indices of successful learning activity of students.

2. To empirically identify the specific character of learning activity success in students having various individual and typological particularities.

3. To determine the contribution of cognitive and motivational characteristics into learning activity success in students having different brain function lateralization.

The object: learning activity success of higher education institution students.

The subject: cognitive and motivational determinants of learning activity success in students having different brain function lateralization.

Hypotheses:

1. There is a specific connection between the individual and typological particularities (lateralization of brain function) and the effective and structural indices of learning activity success in higher education institution students.

2. The contribution of cognitive and motivational characteristics into learning activity success in students having different brain function lateralization type is of a differentiated nature.

\subsection{Empirical research methods}

1) The indices of learning activity success were determined using the following: a) N.V. Nizhegorodtseva's "Integrated diagnostics of students' readiness for studying at higher education institutions" technique (structural index); b) qualitative analysis of academic achievement during the intermediate and final assessment (effective index).

2) For determining the type of interhemispheric brain function lateralization, the functional tests were used. The technique is based on determining the sensory (sight and hearing lateralization) and motor (arms and legs function lateralization) lateralization of brain function.

The research base: the empirical study was conducted on the base of K.D. Ushinskiy Yaroslavl State Pedagogcial University (YSPU). The total scope of sample is 255 students of pedagogical and social specialties and directions. The research was conducted within 2007-2011.

For statistical processing of the findings, the methods of primary descriptive statistics (calculation of percentiles, average values etc.) were used, as well as parametrical (Student t-test) and non-parametrical (Friedman X2-test, K-S Kolmogorov-Smirnov test) methods of data analysis; multiple regression data analysis, correlation data analysis (Pearson r-criterion); the statistical express x2 method and the analysis according to generalized structural indices (Karpov, 2012).

\section{Results and Discussion}

As a result of functional tests, three students groups having different brain function lateralization type were singled out in the study sample: ones having the right-sided LBF (dextrocerebral ones), and ones having the left-sided LBF type (sinistrocerebral ones). For ensuring the integrity of tests, the method of polar groups was used, i.e. students included into the ambidextrous group were not studied.

At the first stage of the work, the values of effective index of learning activity success (the level of academic achievement according to the results of intermediate assessment - exam session) were determined in students having different brain function lateralization (Table 1). 
Table 1. Effective index of learning activity success in students having different lateralization of brain function

\begin{tabular}{|l|c|c|c|}
\hline LBF type & Profile subjects (Mx) & Non-profile subjects (Mx) & Generic achievement level (Mx) \\
\hline the sinistrocerebrals & 3,87 & 3,88 & 3,88 \\
\hline the dextrocerebrals & 4,04 & 3,88 & 3,92 \\
\hline
\end{tabular}

Analyzing the significance of distinctions with the help of Student t-test has not found any specific features in the development level of the effective index (EI) of learning activity success between the dextrocerebral and sinistrocerebral students. This is why for checking the hypothesis additionally we have determined the partial contribution of achievement in profile and non-profile subjects to the effective index of learning activity success. It has been found that in dextrocerebral students the contribution of achievement in profile subjects is higher $(r=0,912 ; p \leq 0,001)$ than that in nonprofile ones $(r=0,896 ; p \leq 0,001)$. Meanwhile, in the sinistrocerebrals, the result is the opposite: the non-profile subjects achievement contribution is higher $(r=0,888 ; p \leq 0,001)$ than the achievement in profile ones $(r=0,868 ; p \leq 0,001)$.

Thus, the analysis of obtained values of learning activity success in different LBF type students allows concluding that the effective index of learning activity success does not differ statistically in the sinistrocerebral and dextrocerebral students. The findings enable us to say that the dextrocerebral students' orientation to high results in profile subjects, and the sinistrocerebrals' one to non-profile subjects corresponds to the described in literature ideas about the motivational and cognitive characteristics of brain function lateralization, interests and the way of thinking of people having different brain function lateralization type.

At the second stage of the research, the structural index (SI) of learning activity success was analyzed in students having different LBF type. The following results were obtained (see Table 2).

Table 2. The development level of components of the psychological structure of learning activity in students having different lateralization of brain function

\begin{tabular}{|c|c|c|c|c|}
\hline No. & PSLA unit & PSLA components & sinistrocerebrals $\mathrm{Mx}$ & Dextrocerebrals Mx \\
\hline \multirow{4}{*}{1.} & \multirow{4}{*}{ Personality and motivation unit } & Need of achievement (NA) & 2,331 & 2,282 \\
\hline & & Empathy (EM) & 2,252 & 2,393 \\
\hline & & Sociability (S) & 2,536 & 2,502 \\
\hline & & The attitude to oneself (AO) & 2,961 & 2,890 \\
\hline \multirow{2}{*}{2.} & \multirow{2}{*}{ Study task acceptance unit } & Acceptance of tasks (TA) & 2,699 & 2,517 \\
\hline & & Professional focus (PF) & 2,890 & 3,045 \\
\hline 3. & $\begin{array}{l}\text { The unit of ideas about the content and } \\
\text { ways of performance of the learning activity }\end{array}$ & Input skills (IS) & 1,584 & 1,656 \\
\hline \multirow{5}{*}{4.} & \multirow{5}{*}{$\begin{array}{l}\text { The unit of qualities ensuring reception, } \\
\text { processing and storage of study information }\end{array}$} & Productivity of attention (PA) & 3,184 & 3,195 \\
\hline & & Logical memory (LM) & 2,636 & 2,169 \\
\hline & & Logical thinking (LT) & 2,587 & 2,455 \\
\hline & & Verbal memory (VM) & 1,691 & 1,760 \\
\hline & & Flexibility of thinking (FT) & 3,539 & 3,389 \\
\hline \multirow{2}{*}{5.} & \multirow{2}{*}{ Learning activity control unit } & Voluntary regulation of activity (VRA) & 2,188 & 2,156 \\
\hline & & Capacity to study (CS) & 0,767 & 0,965 \\
\hline
\end{tabular}

Staying within the framework of assumption about the partial input of cognitive and motivational components into the values of learning activity success indices in students having different LBF type, we believe the use of structural and functional analysis to be quite justified. The analysis of intercorrelation matrices allows constructing a correlation diagram (structure diagram) of the psychological structure of learning activity, which is convenient as such graphic representations are better readable, usable and compact (Figure 1). 


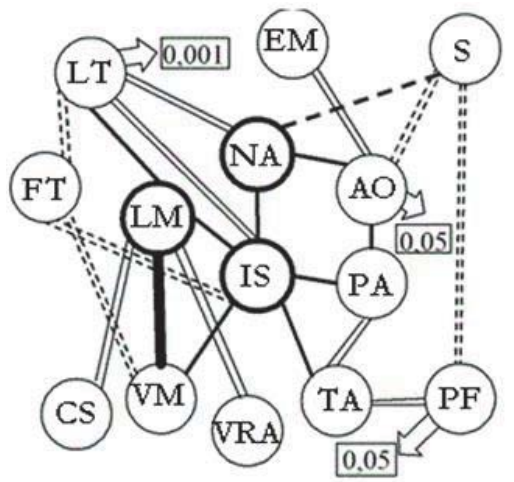

Figure 1. Psychological structure of learning activity in sinistrocerebral students

Note. The conventional signs hereinafter are as follows: 1. $=$ positive correlations at the significance level of $p \leq 0,05$;

positive correlations at the significance level of $\mathrm{p} \leq 0,01$;

$\underline{p \leq 0,01 ;}$ positive correlations at the significance level of $p \leq 0,001$.

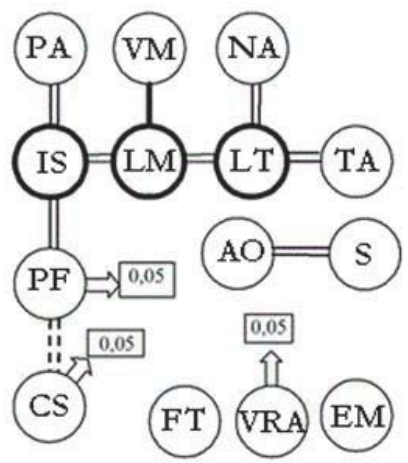

Figure 2. Psychological structure of learning activity in dextrocerebral students

$\Sigma \Sigma=\Sigma$ megative correlations at the significance level of $p \leq 0,05$;

- घ negative correlations at the significance level of $p \leq 0,01$

......... negative correlations at the significance level of $p \leq 0,001$.

2. LM - logical memory; IS - input skills; PA - productivity of attention; FT - flexibility of thinking; AO - the attitude to oneself; NA - need of achievement; TA - acceptance of tasks; PF - professional focus; VRA - voluntary regulation of activity; CS - capacity to study; EM - empathy; S - sociability.

3. - the presence of relation between the structure component and the El of learning activity success; 0,05 significance level of the relation between the component and the El of learning activity success.

During the statistical analysis, the following results were obtained: 1) the psychological structure of learning activity in sinistrocerebral students is formed and has a complete set of components related to all functional units and inherent in higher education institution students' PSLA; 2) the psychological structure of learning activity in sinistrocerebral students is formed and has a complete set of components related to all functional units incorporated in the psychological structure of learning activity. The most significant qualities in the structure are the following academically important qualities: input skills (7 links with other AIQ in the structure), logical memory (5 correlations).

The basic AIQ (having the greatest weight in the structure) are the components of "input skills", "need of achievement" and "logical memory", i.e. the "core" of the psychological structure of learning activity is made up by the AIQ belonging to the "cognitive" and "motivational" units.

The leading AIQ (making strong correlation links with the effective index of learning activity success (the academic achievement level)) in PSLA are the "attitude to oneself" ( $r=0,152 ; p \leq 0,05)$, "logical thinking" $(r=0,287 ; p \leq 0,001)$, and "professional focus" $(r=0,124 ; p \leq 0,05)$. The results obtained allow saying that the learning activity success in sinistrocerebral students is actually determined by the motivational and cognitive components of PSLA.

As the statistical analysis has demonstrated, PSLA of dextrocerebral students includes eleven components of the fourteen which were singled out during theoretical analysis: such AIQ as empathy, flexibility of thinking, voluntary regulation of activity did not enter the structure. However, on balance, the AIQ represented in the psychological structure of learning activity belong to all five units that are characteristic for higher education institution students' PSLA.

In PSLA, the most important AIQ and basic ones are represented by the identical set of components: the input skills, logical thinking, and logical memory (three correlations with other AIQ in the structure). The academically important qualities "verbal memory" and "professional focus" are rather significant (2 correlations). The AIQ "attitude to oneself" and "sociability" are not in the composition of PSLA in this students group and form a significant positive relation between themselves.

The correlations with the effective index of learning activity success (i.e. the leading AIQ) are formed by such academically important qualities as "voluntary regulation of activity" $(r=-0,364 ; p \leq 0,05)$, "professional focus" ( $r=0,338$; $p \leq 0,05)$, and "flexibility of thinking" $(r=0,446 ; p \leq 0,05)$. Thus, the units incorporating the most significant AIQ are the unit 
of ideas about the content and ways of performance of the learning activity and the information unit.

The main distinctions between the indices of the psychological structure of learning activity in students having different LBF type are shown in Table 3.

Table 3. The main indices of the psychological structure of learning activity in students having different brain function lateralization type

\begin{tabular}{|c|l|c|c|}
\hline No. & PSLA indices & the sinistrocerebrals & the dextrocerebrals \\
\hline 1. & The quantity of structure components & 14 & 11 \\
\hline 2. & The total quantity of links between the components in the structure & 44 & 18 \\
\hline 3. & The quantity of strong $r$ relations & 20 & 4 \\
\hline 4. & The average weight of AIQ in the structure & 4,7 & 1,8 \\
\hline 5. & Basic AIQ & IS; LM; NA. & IS; LM; LT. \\
\hline 6. & Leading AIQ & PF; AO; LT. & PF; VRA; FM. \\
\hline
\end{tabular}

The comparative analysis (Table 3) has demonstrated that the sinistrocerebral students have a more developed psychological structure of learning activity as it includes all components - unlike the dextrocerebral students whose PSLA consists of eleven academically important qualities. In the sinistrocerebral group, the quantity of AIQ relations in PSLA is over 2 times as high as that of relations in the dextrocerebral students. The structures also differ according to the average weight index of each component: in sinistrocerebral students, the average AIQ weight equals 4,6 units while it is 1,8 units in the dextrocerebral ones. This means that the role of each academically important quality in the psychological structure of learning activity is higher and more reliable in the sinistrocerebral students.

Table 3 shows that the basic academically important qualities in of sinistrocerebral students are represented by the unit of ideas about the content and ways of performance of the learning activity, the information unit, and the personality and motivation unit. Meanwhile, in dextrocerebral students, the information unit is pronounced as well as the one associated with ideas about the content and ways of performance of the learning activity.

For both dextrocerebral and sinistrocerebral students, the shared leading academically important quality in PSLA is the "professional focus" while other leading AIQ differ. In the sinistrocerebrals, the leading academically important qualities belong to the unit associated with ideas about the goals of activity, personality and motivation unit, and information unit. In the dextrocerebral students, they belong to the activity control unit, personality and motivation, and information ones.

The significant distinctions in the level of development of academically important qualities in students having different brain function lateralization type were obtained: there are distinctions in the extent of "logical memory" AIQ $(t=3,211 ; p \leq 0,01)$.

Thus, the data of Figure 1 and Table 3 allow us to say that the psychological structures of learning activity in different LBF type students are quite singular: on the one hand, statistically, the PSLA of the dextrocerebrals is less developed than in the sinistrocerebral students, yet certain qualitative uniformity (homogeneity) of the structures has to be emphasized - there is partially similar set of basic and leading AIQ and the similar character of their relations. In connection to this, we have conducted a further check of homogeneity / heterogeneity of PSLA in students having different LBF type (Table 4) using A.V. Karpov's express x2 method. The psychological structures of learning activity proved to be homogeneous $r=0,673 ; p \leq 0,01$.

Table 4. Correlation coefficients reflecting the extent of homogeneity / heterogeneity of the psychological structures of learning activity in students having different LBF type

\begin{tabular}{|c|c|c|}
\hline & the sinistrocerebrals & the dextrocerebrals \\
\hline the sinistrocerebrals & 1,00 & $0,673, p \leq 0,01$ \\
\hline the dextrocerebrals & $0,673, p \leq 0,01$ & 1,00 \\
\hline
\end{tabular}

In order to additionally verify the hypothesis, we analyzed the contribution of academically important qualities into the development level of effective and structural indices of learning activity success in groups of students having different LBF type which is expressed as the regression equation (Ledovskaya, 2010) as follows.

- In dextrocerebral students:

The effective index $=0,282$ (logical thinking) - 0,193 (verbal memory). The regression equation explains $16,1 \%$ of 
dispersion of the depending variable and is significant according to Fisher criterion ( $F=8,898 ; p=0,001)$ : the higher the development level of "logical thinking" and the lower "verbal memory" is, the higher the effective index of learning activity success proves to be (the order of AIQ means the extent of significance of its contribution to the index of learning activity success);

The structural index $=0,271$ (attitude to oneself) $+0,258$ (voluntary regulation of activity) $-0,256$ (flexibility of thinking) $+0,212$ (acceptance of tasks). The regression equation explains $73 \%$ of dispersion (it is significant according to Fisher criterion $\mathrm{F}=43,742 ; \mathrm{p}=0,001$ ), i.e. the $\mathrm{SI}$ of learning activity success is the higher, the lower the development level of "flexibility of thinking" is and the higher the "voluntary regulation of activity", "flexibility of thinking", "acceptance of tasks" are.

- In students having the sinistrocerebral LBF type:

The regression equation for the contribution of academically important qualities into the development level of the effective index of learning activity success is impossible;

The structural index $=0,481$ (flexibility of thinking) $+0,480$ (voluntary regulation of activity) $+0,363$ (input skills). The regression equation explains $56,7 \%$ of dispersion and is significant according to Fisher criterion $(F=9,602 ; p=0,001)$ : the higher the development level of the components "flexibility of thinking" and "voluntary regulation of activity", the higher level the structural index of learning activity success wins.

By and large, the following can be pointed out:

1) the psychological structure of learning activity of dextrocerebral students proves statistically to be less developed than the PSLA of the sinistrocerebrals. The PSLA of sinistrocerebral students is characterized by the complete set of the components having the optimum quantity of links between the academically important qualities. The level and quality of development of PSLA is determined by the total of cognitive and motivational set of the academically important qualities. This fact can be explained by the PSLA of dextrocerebrals being more "flexible" and in the process of restructuring up to goals and objectives of the beginning of higher education institution studies.

2) the psychological structures of learning activity of students having different LBF type are characterized by relative singularity: the composition of basic and leading AIQ forming its basis is viewed to be dissimilar. The leading AIQ in the sinistrocerebrals are "professional focus", "logical thinking", "attitude to oneself". In the psychological structure of learning activity of dextrocerebral students, the leading AIQ are "flexibility of thinking", "professional focus", "voluntary regulation of activity". The fact that "professional focus" is the leading academically important quality in students of both groups (i.e. its development level contributes to the rise of learning activity success) is crucial, because V.D. Shadrikov points out that "when choosing a profession, man as if "projects" the motivational structure on the structure of factors associated with the professional activity via which needs can be satisfied" (Shadrikov, 1982). "The acceptance of a profession generates a wish to perform it in a certain way, a certain determining trend and serves as the starting point for forming the psychological system of the activity" (Shadrikov, 1982). The motivation organizes integral behavior, increases the activity, produces an essential effect on forming the goal and choosing the ways for achievement thereof (Shadrikov, 2009). Thus, motivation produces a learning activity genesis effect on students at the initial stage of higher education institution studies.

Due to the sample encompassing mainly the students of humanitarian specialities and directions of study, the data obtained about the specific nature of leading and basic academically important qualities in students are in line with the ideas reflected in literature as for the ways of thinking, professional orientation, and cognitive styles of students having different LBF types.

The findings of the research conducted and regression data analysis results allow wording the following recommendations for enhancing the values of effective and structural indices of learning activity success:

- for the dextrocerebrals: the effective index can be enhanced by reducing the development level of verbal memory and increasing the values of logical thinking; the structural index - by reducing the role of flexibility of thinking and increasing the values of such components as "attitude to oneself", "voluntary regulation of activity", "acceptance of tasks";

- for the sinistrocerebrals: the increase of effective index of learning activity success is hard to be influenced by developing certain academically important qualities as all components ensure high El figures; the structural index of learning activity success will be increased as the development level of voluntary regulation of activity, flexibility of thinking, input skills goes up;

- $\quad$ for dextrocerebral students, it is better to use the individual home assignments techniques, and written form reporting is recommended for such students. It should be borne in mind that the dextrocerebrals are incapable 
of solving the logical and mathematical problems as precisely as the sinistrocerebrals do. It is also essential to develop a plan of study assignments performance for the sinistrocerebrals in order to develop the learning activity regulation components in them;

- training classes should be organized for students having a low structural index of learning activity success for them to develop the academically important qualities characterized by a low development level. The academically important qualities which essentially contribute to the values of structural and effective indices of learning activity success have to be emphasized. The classes have to be aimed at both improvement of generic mental abilities development and enhancement of motivation for learning, development of cognitive qualities allowing the students to organize and control their activity;

- $\quad$ the students having high values of structural index of learning activity success also should be involved into training classes, first of all, because the academically important regulation, motivation, goal- and skill-related, information qualities they already have need to be developed further, with the learning activity being diverse at higher education institutions;

- $\quad$ the students having a low effective index of learning activity success have to be involved into work bringing about the formation in them of components essential for performing the learning activity at the higher education institution: first, the motivation for higher education institution learning, the professional focus and generic intellectual capacities. It should also be noted that "sociability" as an academically important quality plays a negative part in the values of the effective index;

- the academic activity of students having the average and high values of the effective index have to be occasionally motivated and stimulated, they have to be encouraged for careful performance of tasks.

We should also mention that the problem of increasing the students' learning activity success by taking into account the individual and typological particularities is complicated and multi-faceted; it involves not only the university professors and teaching staff but also the students themselves, the curators of groups, the work of psychological services of higher education institutions. The problem of increasing the students' learning activity success is complicated also because it is based on enhancing the motivational, reflexive (Shadrikov, 2013), and cognitive development (that of thinking, first of all) of a student as a professional. As M.M. Kashapov points out: "Formation of thinking is the changing of previously formed particularities of a professional's thinking due to the necessity of bringing it in line with the new requirements. The professionalism of thinking is manifested in the ability to see the trend of modern production problems and to find the most efficient means for resolving them" (Kashapov and Leybina, 2009).

\section{Conclusion}

Thus, the specific character of learning activity success in students having different LBF type has been revealed. With identical values of the learning activity structural index, the originality of the component, structural and functional composition of PSLA has been proved which is explained by the particularities of students' cognitive processes and behavioral characteristics.

The results of the research allow highlighting the following directions of work as promising ones: expanding the analysis of cognitive and motivational components incorporated into the psychological structure of learning activity, their contribution to the success of learning activity; the analysis of cognitive and motivational aspects of the learning activity success, during the academic and professional learning activity; elaborating the individual and typological particularities and success of learning activity in students of humanitarian, technical, natural sciences specialities; revealing the specific nature of individual and typological particularities and success of the learning activity in students of various higher education institutions.

\section{Acknowledgements}

The work was performed with the financial support of project No. 25.2356.2014K within the project part of the state R\&D assignment for the higher education institution.

\section{References}

Kashapov, M.M., Leybina, A.V. (2009) Motivation of professional creative thinking. Psychology in Russia: State of the art, 585-602.

Karpov A.V. (2012). The Integral Abilities of the Personality as the Subject Matter of Psychological Research. Psychology in Russia: State of the Art, 5, 99-116. 
Ledovskaya, T.V. (2010). Individualno-tipologhicheskie osobennosty studentov vuza s raznymi pokazatelyami uspeshnosty uchebnoi deyatelnosty [Individual and typological features of students with different indicators of success of educational activity]. Yaroslavl: Izdatel'stvo YSPU.

Nizhegorodtseva, N.V. (2004). Systemoghenetichesky analiz gotovnosti k obusheniu [Sistemogenetichesky analysis of readiness for training]. Yaroslavl: Izdatel'stvo Avers Press.

Povarenkov, U.P. (2013). Problemy psikhologhii professionalnogo stanovleniya lichnosty [Problems of psychology of professional formation of the personality]. Saratov.

Shadrikov, V.D. (2009). Ot individa k individualnosti: Vvedenie v psikhologhiyu cheloveka [From the individual to identity: Introduction to psychology]. Moscow: RAS Institute of psychology publishing house.

Shadrikov, V.D. (1982). Problemy sistemogheneza professionalnoi deyatelnosti cheloveka [Problems of systemogenesis of human professional activity]. Moscow: Izdatel'stvo Nauka.

Shadrikov, V.D. (2013). The role of reflection and reflexivity in the development of student's abilities Psychology in Russia: State of the Art, 55-64.

Shadrikov, V.D. (2012). Student's development in the learning process. Psychology in Russia: State of the Art, 388-404. 